\title{
A Reflection on Assessment and Treatment of Generalized Anxiety Disorder in Child, Adolescent, and Adult Populations
}

\author{
Phillip Radetzki and Kendall Deleurme \\ Department of Psychology, MacEwan University, Edmonton, Alberta \\ Corresponding author: radetzkip@mymacewan.ca
}

\section{ABSTRACT}

Generalized anxiety disorder (GAD) was initially introduced in the revised third edition of the Diagnostic and Statistical Manual of Mental Disorders (DSM-III-R) as a diagnosis to help characterize chronic and excessive worry. Today, GAD is one of the most common anxiety disorders in the general population and practice. Although GAD is an increasingly popular area of research, it remains in a premature state. This is evident by a lack of empirically supported assessment measures, intervention strategies, and treatment options. The purpose of this paper is to briefly review current empirically based assessment and treatment interventions for GAD commonly used in child, adolescent, and adult populations.

Worry is common in everyday functioning (Borkovec \& Inz, 1990). However, when one's level of worry progresses to an extent that it seems uncontrollable and begins interfering with normative functioning, intervention may be required. Generalized Anxiety Disorder (GAD), introduced in the third edition of Diagnostic and Statistical Manual of Mental Disorders (DSM-III-R), is a chronic and pervasive disorder characterizing unremittent and excessive worry (American Psychiatric Association, 1987; Roemer \& Orsillo, 2002). The DSM-V identifies GAD as excessive anxiety and uncontrollable worry across a variety of domains that lasts at least six months, causing clinically significant distress and including at least three of the following symptoms: muscle tension, restlessness, difficulty concentrating, fatigue, irritability, and/or sleep disturbance (American Psychiatric Association, 2013).

GAD is among the most common anxiety disorders encountered in the general population and practice (Spitzer, Kroenke, Williams, \& Löwe, 2006; Statistics Canada, 2015). The lifetime prevalence rate of GAD in the general population is $5 \%(\sim 3.6 \%$ and $\sim 6.6 \%$ for males and females, respectively; Waddell, Shepherd, Schwartz, \& Barican, 2014), and between $2.8 \%$ and $8.5 \%$ in medical practice (Spitzer et al., 2006). Further, $\sim 3 \%$ of the general population in Canada has a diagnosis of GAD (Statistics Canada, 2015). Of this 3\%, $\sim 0.7 \%$ are children and adolescents (C/As) between 4-17 
years (Waddell et al., 2014). However, these estimates are conservative; far more individuals likely suffer from the associated symptoms, yet lack a diagnosis (Waddell et al., 2014).

With C/A populations, the nature of worry in this period of development makes it difficult to differentiate normal levels from excessive (Cheng \& Myers, 2011). Typical worry content in C/As with GAD pertains to the health of self and of significant others, school performance, appearance, and familial conflict (Cheng \& Myers, 2011). A unique assessment factor in the DSM-V for diagnosing $\mathrm{GAD}$ in $\mathrm{C} / \mathrm{A}$ populations is the requirement of only one GAD-associated symptom, as compared to three for adult populations (Cheng \& Myers, 2011). This unique factor represents findings that mental disorders are the greatest risk to $\mathrm{C} / \mathrm{As}$ health in Canada (Waddell et al., 2014). Yet, many C/As facing mental health issues, such as GAD, are not receiving the support needed (Waddell et al., 2014). In Canada, only 1 -in-5 C/As requiring mental health services are receiving them (Canadian Mental Health Association, 2016). The lack of available support is having detrimental effects on $\mathrm{C} / \mathrm{As}$, such as increased rates of suicide (Canadian Mental Health Association, 2016). It is critical that $\mathrm{C} / \mathrm{As}$ with symptoms of GAD receive immediate and effective intervention, with the goal being to reduce overall impairment and guide them toward their highest potential (Waddell et al., 2014).

While C/As with GAD struggle to acquire support in terms of treatment, adult populations experience their own challenges. GAD is commonly conceptualized as reflecting the central process of all emotional disorders (e.g., Barlow, 2004). Consequentially, much of GAD research within this population is riddled with varying conceptual definitions and diagnostic criteria (Wittchen \& Hoyer, 2001). To account for this, research has recently focused on examining the effectiveness of existing GAD treatment models and how they may be altered and/or combined to produce novel interventions (Huppert \& Sanderson, 2010). While this approach is promising, a greater understanding of GAD etiological factors may help researchers and clinicians form more effective prevention and treatment methods for adults.

There are currently five major models of GAD (Behar, DiMarco, Hekler, Mohlman, \& Staples, 2009):

- The Avoidance Model of Worry and GAD (AMW; Mowrer, 1947), arguing that word-based worry inhibits mental imagery in an attempt to manage anxiety.

- The Intolerance of Uncertainty Model (IUM; Dugas, Gagnon, Ladouceur, \& Freeston, 1998), emphasizing that the stressful and overwhelming nature of uncertain situations.

- The Acceptance Based Model (ABM; Roemer \& Orsillo, 2002), proposing that individuals with GAD negatively react to internal experiences, and use worry to avoid these experiences.

- The Emotion Dysregulation Model (EDM; Mennin, et al., 2002), focusing on issues with emotion regulation.

- The Metacognitive Model of Worry (MCM; Wells, 1995), suggesting individuals with GAD have negative beliefs about their worry.

Of these five models, the AMW is the most commonly discussed in C/A populations (Borkovec, Alcaine, \& Behar, 2004). According to the AMW, worry is primarily word-based (i.e., experiencing worry via thoughts) as opposed to imagery-based (i.e., experiencing worry via mental images; Borkovec et al., 2004). Anxiety results from imagining a feared potential future event - the purpose of worrying is to inhibit this mental imagery to control the anxiety. However, this strategy is often ineffective. Despite this, the AMW proposes that C/As with GAD still see worry as a coping mechanism, as it is at times negatively reinforced (Borkovec \& Roemer, 1995). It 
is hypothesized that early exposure to significant stress and trauma increases the likelihood of a C/A developing GAD (Borkovec et al., 2004). These C/As lack opportunities to build effective coping mechanisms and thus struggle with uncertain events, leading to excessive worry and anxiety. Furthermore, the AMW argues that when a child develops an insecure attachment style to parental figures, this encourages viewing the world as a generally dangerous place, in turn increasing the chances of developing GAD (Borkovec et al., 2004; Cassidy, Lichtenstein-Phelps, Sibrava, Thomas, \& Borkovec, 2009).

In adult populations, Newman and colleagues (2013) identify environmental, attachment and parenting style, and temperament as risk factors for GAD development. Environmental factors include unexpected life factors, maltreatment, and loss, which can contribute to a questioning of values, beliefs, and overall outlook on life. Attachment and parenting style, as previously mentioned, affect emotion regulation, at which patterns of insecure attachment increase the risk of developing GAD. Additionally, negative parenting behaviors, such as parental rejection and harsh discipline, are associated with offspring worry and adult-onset GAD. The last risk factor identified (Newman et al., 2013), temperament, describes individual dispositions in biological, behavioral, and emotional responsiveness to environmental stimuli. The tendency to be easily aroused in midchildhood, for instance, is associated with the development and maintenance of GAD symptoms.

Although GAD is an increasingly popular area of research with several models available to explain its nature, the area is nevertheless in a premature state (Mennin, Heimberg, Turk, \& Fresco, 2002). The objective of this paper is to provide a brief review of current empirically-based assessment measures and treatment interventions for GAD across $\mathrm{C} / \mathrm{A}$ and adult populations. While other reviews focus on C/A (e.g., Wagner, 2001) and adult (e.g., Locke, Kirst, \& Shultz, 2015) populations individually, to the authors' knowledge, few include all age ranges. Furthermore, this article intends to provide a foundation for understanding current conceptualizations of GAD among an interdisciplinary audience.

\section{Assessment}

\section{Children and Adolescents}

GAD in C/As is typically chronic and has greater comorbidity with other disorders compared to adult-onset, making early detection essential (Cheng \& Myers, 2011). It is recommended that assessment includes a clinical interview with the child and guardian independently, the completion of objective ratings scales by several informants, and alternative explanations for symptoms be ruled out (Cheng \& Myers, 2011). Additionally, assessment of risk to clients' safety, developmental levels, triggers, and environmental factors should be considered (Cheng \& Myers, 2011). While several self-report scales are available to assist clinicians in differentiating typical levels of daily worry from that which is abnormal, many of these tools are specific to adult populations (Behar et al., 2009). A direct implication of insufficient research regarding $\mathrm{GAD}$ in $\mathrm{C} / \mathrm{As}$ is a lack of assessment measures. Of the limited assessment measures available, the authors suggest that few appear to be popular among clinicians. There are measures for C/As independently, and those that can be administered to both populations. The following GAD assessment tools for C/A populations are highlighted in the present paper: the Anxiety Disorders Interview Schedule for Children and Parents (ADIS-C/P; Silverman \& Nelles, 1988); the Youth Anxiety Measure for DSM-5 (YAM-5; Muris et al., 2017); and the Severity Measure for Generalized Anxiety Disorder (Craske et al., 2013).

The ADIS-C/P

The ADIS-C/P is a semi-structured interview intended for child populations in addressing various anxiety disorders, including: generalized 
anxiety disorder, separation anxiety disorder, panic disorder, specific phobias, social phobia, and obsessive-compulsive disorder (Silverman \& Nelles, 1988). Administered by clinicians, it is completed by the child (ADIS-C) and guardian (ADIS-P). The ADIS-C/P consists of measuring the presence and severity of anxiety and related symptoms, investigating both level of distress and impairment of normative functioning.

Following the interviews, the total "yes" responses (i.e., indicating presence of symptom[s]) in both the ADIS-C and ADIS-P are added to obtain a total score. The total score is then compared against the GAD cut-off score. If GAD criteria are met, the child and guardian are asked if these symptoms in their entirety lead to significant interference and impairment in the child's daily functioning. Impairment ratings are scored on a 9-point scale via a feeling thermometer. The feeling thermometer scores from the child and guardian are individually compared to the scores constituting a diagnosis as outlined in the manual. If both parties agree, a diagnosis of GAD is made, with the higher of the two scores being assigned to the child. The ADIS-C/P demonstrates strong psychometric properties, constituting an acceptable assessment tool (Silverman, Saavedra, \& Pina, 2001).

\section{The YAM-5}

The YAM-5 is an assessment measure intended for use with adolescents (Muris et al., 2017). This self-report questionnaire, administered by clinicians to the adolescent and guardian, assesses symptoms pertaining to all anxietyrelated disorders. This tool assesses the adolescent's level and quantity of anxiety and worry, helping decipher which of the anxiety disorders is the most appropriate diagnosis. This measure is divided into two sections: part one, consisting of 28 items measuring the anxietyrelated disorders, including panic disorder and GAD; and part two, consisting of 22 items focusing on specific phobias. Regarding GAD, there are six specific items assessing associated symptoms. The YAM-5 demonstrates good psychometric properties, supporting its use in assessment (Simon, Bos, Verboon, \& Muris, 2017). Additional benefits include its brief length, cost-effectiveness, and utility in situations where a typical diagnostic interview is not achievable.

The Severity Measure for GAD

The Severity Measure for GAD is a 10 -item selfreport questionnaire intended for both $\mathrm{C} / \mathrm{As}$ (Craske et al., 2013). This measure was developed for administration both upon a GAD diagnosis and throughout treatment. Interval lengths between each administration is dependent upon symptom severity and treatment status. It is advised that the Severity Measure for GAD is not the sole measure in assessing GAD symptom severity as it evaluates client's' thoughts, feelings, and behaviors during the week prior to assessment. As such, it should be used in addition to other tools throughout diagnosis and treatment. Questions on the Severity Measure investigate the $C / A^{\prime}$ 's functioning in various areas of daily life, such as in the family, health, and school environment. Unlike other assessment tools developed for C/A onset GAD, the Severity Measure for GAD is not completed by a guardian. Clients rate themselves on a 5-point scale for each symptom listed. Investigation into this measure suggests good reliability and validity, supporting its use with clinical populations (Craske et al., 2013).

Adults

Unfortunately, limited research efforts focused toward GAD upon its introduction in the DSMIII-R has impacted the quality of assessment approaches for adult populations. Concerning the current instruments used to assess anxiety, Spitzer et al. (2006) state, "measures of anxiety are seldom used in clinical practice because of their length, proprietary nature, lack of usefulness as a diagnostic and severity measure, and requirement 
Table 1: Summary of GAD assessment tools for children and adolescents.

\begin{tabular}{|c|c|c|c|}
\hline Format & $\begin{array}{c}\text { The Anxiety Disorders } \\
\text { Interview Schedule for } \\
\text { Children (ADIS-C/P) }\end{array}$ & $\begin{array}{c}\text { The Youth Anxiety Measure for } \\
\text { DSM-5 (YAM-5) }\end{array}$ & The Severity Measure \\
\hline Method & $\begin{array}{c}\text { Measures the presence } \\
\text { and severity of anxiety and } \\
\text { related symptoms and levels } \\
\text { of distress and impairment } \\
\text { such symptoms have on daily } \\
\text { functioning }\end{array}$ & $\begin{array}{c}\text { Self-report questionnaire } \\
\text { Assesses level and quantity } \\
\text { helping decipher which of the } \\
\text { anxiety disorders is the most } \\
\text { appropriate diagnosis }\end{array}$ & $\begin{array}{c}\text { Evaluates one's thoughts, feel- } \\
\text { ings, and behaviors throughout } \\
\text { the course of a week, including } \\
\text { in the context of family, health, } \\
\text { and school }\end{array}$ \\
\hline
\end{tabular}

of clinician administration rather than patient self-report" (p. 1092). Difficulty differentiating symptoms of GAD from other disorders is a second key barrier in assessment. Specifically, symptoms of anxiety disorders often overlap, making GAD commonly comorbid with other disorders (Rapee, 1991). For instance, Eisenberg and colleagues (2007) report that $50.1 \%$ of individuals who screen positive for major depression also present GAD symptoms. The fourth edition of the GAD questionnaire (GAD-Q-IV; Newman et al., 2002), the Penn State Worry Questionnaire (PSWQ; Meyer, Miller, Metzger, \& Borkovec, 1990), and the GAD-7 (Spitzer et al., Löwe, 2006) are three instruments that will be highlighted, while Table 2 below provides a summary.

GAD-Q-IV

The GAD-Q-IV is founded on the GAD-Q, which was developed as an initial screening device to identify individuals with GAD. Though initially effective, the utility of the GAD-Q diminished as conceptualizations of GAD evolved (Newman et al., 2002). For instance, Newman et al. (2002) note that the GAD-Q defines pathological worry as unrealistic or excessive, regarding at least two life circumstances, and with the presence of at least 6 of 18 possible symptoms. These symptoms can include feelings of restlessness, irritability, and fatigue. The GAD-Q-IV, however, defines pathological worry as being excessive and uncontrollable, pertaining to a variety of life events or activities, and with the presence of at least 3 of 6 symptoms considered as primary. Further, a critical difference between the GAD-Q and the GAD-QIV is that while the GAD-Q requires symptoms to be "often present when anxious," the GAD-Q-IV requires that clients experience the symptoms "more days than not" (Newman et al., 2002, p. 217). In terms of validity, Newman et al. (2002) report that the GAD-Q-IV is successful in differentiating GAD from other anxiety disorders, with $93 \%$ of clients with GAD producing a higher score on the scale than clients with different anxiety disorders. Overall, the GAD-Q-IV is considered an efficient and valid self-report measure for GAD that can be relied upon as an initial screening device. It is capable of decreasing the costs - whether timebased, financial, or otherwise - that are associated with approaches characterized by a series of clinical interviews (Newman et al., 2002).

PSWQ

The Penn State Worry Questionnaire (PSWQ; Meyer et al., 1990) is a 16-item self-report measure of the tendency to engage in worry. Participants rate themselves on a five-point Likert-type scale on items relating to experience with worry, such as type 
of worry experienced in different situations. The PSWQ demonstrates strong internal consistency and high test-retest reliability (Brown, Antony, \& Barlow, 1992; Meyer et al., 1990). The PSWQ has good criterion and construct validity, making it a valid measure of trait anxiety (Brown et al., 1992; Meyer et al., 1990). Additionally, the PSWQ has high convergent and discriminant validity, further supporting its use (Brown et al., 1992).

\section{GAD-7}

The GAD-7 (Spitzer et al., 2006) is a brief, 7-item self-report anxiety scale designed to identify probable cases of GAD. Participants use a fourpoint Likert-type scale to report the frequency with which they experience the following characteristics: anxiousness, inability to control worry, excessive worry about multiple things, trouble relaxing, severe restlessness, irritability, and fear of awful things happening. The GAD-7 has excellent internal consistency and good testretest reliability (Spitzer et al., 2006). It also has good procedural validity and construct validity, as demonstrated by strong positive associations with multiple domains of functional impairment. Convergent validity was determined by comparing correlations of the GAD scale with both the Beck Anxiety Inventory (BAI) and the anxiety subscale of the Symptom Checklist-90. Collectively, the strengths of the GAD-7 lie in its ability to efficiently assess GAD symptoms across diverse clinical settings, while also differentiating any overlap

Table 2: Summary of GAD assessment tools for adults. between anxiety and depression. In addition, the administration of the GAD-7 does not require a clinician - a factor to which Spitzer and colleagues (2006) conclude can provide significant service to those working in busy health settings.

\section{Treatment}

\section{Children and Adolescents}

Though several treatment options are available for $\mathrm{C} / \mathrm{As}$ diagnosed with $\mathrm{GAD}$, such interventions vary in empirical support (Cheng \& Myers, 2011). Oftentimes, treatment is a combination of the several methods. It is cautioned that several treatment routes may be implemented prior to discovering what is most effective and efficient for each individual client. Guidelines for treatment include the following: complete and thorough clinical assessment prior to diagnosis and treatment implementation, consideration of potential/existing comorbid disorders, and to prioritize targeted symptoms and treatment goals (Cheng \& Myers, 2011). Furthermore, family preference, availability of treatment options, economic cost, and duration, need to be considered in treatment development. The most frequently used and strongly supported treatment options for $\mathrm{C} / \mathrm{As}$ highlighted in this paper include cognitive behavioral therapy (CBT) and psychopharmacologic interventions.

\begin{tabular}{|c|c|c|c|}
\hline Format & $\begin{array}{c}\text { Generalized Anxiety Disorder } \\
\text { Questionnaire-IV (GADQ-IV) }\end{array}$ & $\begin{array}{c}\text { Penn State Worry } \\
\text { Questionnaire (PSWQ) }\end{array}$ & $\begin{array}{c}\text { Generalized Anxiety } \\
\text { Disorder 7-Item (GAD-7) }\end{array}$ \\
\hline Method & $\begin{array}{c}\text { Determines clients' pathologi- } \\
\text { cal worry across a variety of life } \\
\text { events/activities, with clients } \\
\text { required to experience symptoms } \\
\text { 'more days than not' }\end{array}$ & $\begin{array}{c}\text { Assesses clients' tendency } \\
\text { to engage in worry, including } \\
\text { their experiences with differ- } \\
\text { ent types of worry in different } \\
\text { situations }\end{array}$ & $\begin{array}{c}\text { Identifies clients' probable } \\
\text { causes of GAD and the } \\
\text { frequency to which such } \\
\text { causes are experienced }\end{array}$ \\
\hline
\end{tabular}


CBT

CBT is a popular intervention tool for C/A-onset GAD (Wehry, Beesdo- Baum, Hennelly, Sucheta, Connolly, \& Strawn, 2015). CBT consists of six fundamental characteristics: psychoeducation, creating management strategies for physical symptoms, cognitive restructuring, developing problem-solving strategies, implementing systematic exposure, and planning for relapse (Velting, Setzer, \& Albano, 2004). The psychoeducation component involves identifying and addressing misconceptions, as well as educating the $\mathrm{C} / \mathrm{A}$ and guardian about the nature of anxiety, how to differentiate normal levels of worry and anxiety from abnormal levels, and the effects of excessive worry and anxiety.

According to Velting et al. (2004), techniques taught to manage physical reactions may include relaxation training or diaphragmatic breathing exercises. The clinician attempts to educate the client about the connection between physiological and emotional arousal and anxiety. Cognitive restructuring involves identifying and challenging specific anxiety-provoking thoughts and images, lessening their degree of presence and effects. Developing problem-solving strategies includes creating and practicing tools for the $\mathrm{C} / \mathrm{A}$ for coping with uncertain events or expected challenges in daily life. Practicing systematic exposure with clients involves exposing clients to their unique feared situation or stimuli, which may include imagination, stimulation, and in vivo methods (i.e., flooding - involving rapid exposure to the feared stimuli, versus systematic desensitization involving gradual exposure). The goal of systemic exposure is to desensitize the individual to their fears. Lastly, relapse prevention planning involves creating strategies for addressing relapse in advance.

It is recommended that CBT takes into account clients' developmental level, potential and/or present comorbid disorders, and level of guardian involvement in maintaining GAD (Cheng \& Myers, 2011). Empirical research provides support for CBTs use with C/A populations (Piacentini et al., 2013). Piacentini et al. (2013) found that when participants with various anxiety disorders (e.g., separation, generalized, and social) were randomly assigned to either three months of CBT, sertraline (SRT), a combination of both, or placebo, participants treated with CBT showed a significant reduction in symptoms. This efficacy remained even at 36 weeks post-treatment for $>80 \%$ of participants. However, evidence suggests that a combination approach, utilizing both CBT and SRT is more efficacious than an independent approach (Piacentini et al., 2013; Walkup et al., 2013).

Although traditional CBT involves a face-toface therapeutic alliance, online-based CBT interventions are also rising in popularity (Spence et al., 2008). Online CBT can help address issues of stigma attached to seeking mental health attention, poor access to services, and financial issues for $\mathrm{C} / \mathrm{As}$ requiring intervention (Spence et al., 2008). For instance, BRAVE-ONLINE is a form of CBT treatment delivered entirely online (Spence et al., 2008). BRAVE-ONLINE aims to be a more accessible and practical mode of intervention. The program consists of 10 weekly C/A sessions, with each session approximately 60 minutes long. Following the 10 initial sessions, two booster sessions are administered at the one month and three month mark. Within the program are sessions specifically for the guardian to complete, aimed at anxiety psychoeducation. Various anxiety management strategies are also included in the program, including: understanding and recognizing physiological and emotional symptoms of anxiety; relaxation strategies; cognitive strategies, such as positive self-talk and cognitive restructuring; graded exposure to specific fears; and selfreinforcement of brave behavior. Finally, weekly homework assignments help further understanding of the strategies taught and provide practice opportunities. Clients' interactions with their internet therapist are limited to an initial telephone 
call to summarize the treatment plan, a midprogram telephone call, and brief weekly emails in which the therapist provides feedback about performance.

However, while results suggest online-based treatments reduce anxiety levels and GAD symptoms (Spence et al., 2008), research also demonstrates that these effects are more substantial if the online therapy is combined with regular in-person interactions with a therapist (Spek et al., 2007). Additional empirical support is needed before adopting online treatment as the standard intervention strategy. Further, while online-based CBT may be a beneficial alternative that is time and cost effective, there remains a lack of opportunity to build rapport and a strong therapeutic alliance (Spek et al., 2007). Although online programs attempt to maintain the therapeutic alliance with an assigned therapist, additional research is needed to determine if these attempts are successful.

\section{Psychopharmacologic Interventions}

Although popular, psychopharmacologic treatments (e.g., Selective Serotonin Reuptake
Inhibitors [SSRIs]) are not highly effective in reducing GAD symptom severity in C/As when used as the only treatment method (Cheng \& Myers, 2011). Research demonstrates that monotherapy with SSRIs is only effective in reducing anxiety in $40-50 \%$ of clients (Cheng \& Myers, 2011). Alternatively, psychopharmacologic treatment is commonly paired with CBT-oriented interventions in treating C/A-onset GAD (Wehry et al., 2015). This likely results from empirical support of combining psychopharmacologic approaches with CBT in adult populations (Wehry et al., 2015). Support for such multimodal treatment plans in C/As are evident in longitudinal analyses, in which $80 \%$ of clients maintain positive response rates at 24 and 36-week follow-ups (Piacentini et al., 2013). It is suggested that a combination of treatments is both durable and sustainable, with remission rates impressively low (Ginsburg et al., 2014).

Although research supports the inclusion of SSRIs in treatment planning, clinicians are advised to consider potential side effects and to perform a cost-benefit analysis prior to administering any medication. Fluoxetine, a common and successful SSRI used in treating C/As with GAD, has various potential adverse side effects including nausea,

Table 3: Summary of GAD treatment options for children and adolescents.

\begin{tabular}{|c|c|c|}
\hline & Cognitive Behavioral Therapy (CBT) & Psychopharmacological Interventions \\
\hline Method & $\begin{array}{l}\text { Client learns about the nature of his/ } \\
\text { her anxiety while building strategies for } \\
\text { managing physical symptoms, prob- } \\
\text { lem-solving skills, and worry tolerance, } \\
\text { while also identifying and challenging } \\
\text { anxiety-provoking thoughts /images }\end{array}$ & $\begin{array}{l}\text { Selective Serotonin Reuptake Inhibitors (SS- } \\
\text { RIs), an oral medication, block the reabsorp- } \\
\text { tion of serotonin in the brain, facilitating the } \\
\text { creation of extra serotonin }\end{array}$ \\
\hline Administration & $\begin{array}{l}\text { Face-to-face or online (e.g., BRAVE-ON- } \\
\text { LINE) }\end{array}$ & E.g., Fluoxetine \\
\hline Effectiveness & $\begin{array}{c}\text { Significant reduction in symptoms last- } \\
\text { ing } 36 \text { weeks post-treatment for }>80 \% \\
\text { of participants } \\
\text { (Piacentini et al., 2013) }\end{array}$ & $\begin{array}{l}\text { Reduces anxiety in } 40-50 \% \text { of clients (Cheng \& } \\
\text { Myers, 2011) }\end{array}$ \\
\hline
\end{tabular}


abdominal pain, drowsiness, and headaches (Beidel et al., 2007). While the use of such medications is superior in efficacy compared to placebos, it is important to consider these potential side effects in treatment planning (Beidel et al., 2007).

Adults

There are various treatment options available for adult-onset GAD, such as applied relaxation (AR), non-directive supportive therapy, and psychoanalytic therapy (Hupport \& Sanderson, 2010). AR was developed in the 1970s and conceptualizes anxiety as interacting with cognitive, physiological, affective, and behavioral systems. AR provides clients with coping skills that prevent their physiological reactions to anxiety from initiating the other systems, therein stopping the cycle of anxiety (Hayes-Skelton \& Roemer, 2013). Non-directive supportive therapy; however, provides clients with an open atmosphere to share and discuss their feelings (Brenes et al. 2015). Similarly, psychoanalytic therapy is based on the idea that unconscious conflicts contribute to or cause ailments (Milton, Polmear, \& Fabricius, 2011). Psychoanalytic therapy helps clients by using techniques such as free association, in which clients say whatever is on their mind (Milton et al., 2011). In addition to $A R$, non-directive supportive therapy, and psychoanalytic therapy, traditional CBT and Acceptance and Commitment Therapy (ACT) have widespread empirical support for their effectiveness in treating GAD (Gould, Otto, Pollack, \& Yap, 1997; Hupport \& Sanderson, 2010; Roemer \& Orsillo, 2007; Wetherell et al., 2011).

CBT

While CBT, a scientifically-based form of psychotherapy, is effective in treating numerous disorders, it has received the most support for alleviating worry and anxiety (Huppert \& Sanders, 2010). CBT is labelled as an "empirically supported treatment" by the Task Force of the Division of
Clinical Psychology of the American Psychological Association (Huppert \& Sanders, 2010). It is distinct in its brief nature, with a tendency to focus on the present and a problem-solving-like approach. Based on the cognitive model, CBT examines the way clients may perceive a situation and identifies the dynamic between such perceptions and their emotions (Beck Institute for Cognitive Behavior Therapy, 2016). A typical CBT intervention for GAD includes cognitive restructuring, relaxation training, anxiety management training, situational and imaginal exposure, and systematic desensitization. These techniques may be applied independently or in combination with each other and other treatments (Gould et al., 1997). Anxiety management training is an especially key CBT technique that clinicians may use with clients suffering from GAD. Anxiety management training involves helping clients focus on their fears of being unable to cope with their excessive and uncontrollable worry (Gould et al., 1997). In addition to combining relaxation and self-talk, this technique utilizes an "image switching" procedure, in which clients are exposed to an anxiety-evoking image only to then adapt a more reassuring image (Gould et al., 1997). In their meta-analysis, Gould and colleagues (1997) report that the average client with GAD needs 9.5 sessions of CBT, with among $30 \%$ to $66 \%$ of clients experiencing improvements in anxiety. This finding aligns with Huppert and Sanderson's (2010) conclusion that approximately $50 \%$ of all clients are considered to be responders to CBT.

\section{$A C T$}

While CBT uses a problem-solving approach, ACT focuses on acceptance. Specifically, acceptance is a process in which clients' psychological flexibility is enhanced to counter experimental avoidance and ineffective coping styles (Luoma, Haynes, and Walser, 2007). Thus, while clinicians approaching treatment for GAD via CBT will attempt to reduce problematic thoughts by investigating their nature and associated consequences, an ACT approach would encourage clients to acknowledge the 
presence of such problematic cognitions and respond appropriately. With $A C T$, the goal is to increase clients' engagement in meaningful activities across various domains of everyday life (Wetherell et al., 2011). In a study by Roemer and Orsillo (2007) investigating the effectiveness of acceptance-based approaches, participants demonstrated significant improvements in GAD, worry, and anxiety. These improvements were maintained upon a 3-month follow-up assessment, with participants reporting significantly improved quality of life. Interestingly, at approximately $50 \%$, Roemer and Orsillo (2007) estimate that $\mathrm{ACT}$ has the same treatment-response rate as CBT for GAD populations. Lastly, Wetherell and colleagues (2011) note that ACT is relatively easy for clinicians to learn - adding to the potential for ACT being used to treat GAD across various mental health settings.

\section{Conclusion}

Despite its increasing prevalence, the GAD research area is generally premature. This is evident by a lack of empirically supported assessment measures, intervention strategies, and treatment options. Historically, anxiety scales have had limited presence in clinical settings due to issues of length, clinician-required administration, and difficulty differentiating between anxiety and comorbid conditions. Regarding treatment, traditional CBT remains the standard approach to GAD due to its empirical support as an effective intervention in C/A and adult populations. While there is strong support for the use of CBT and psychopharmacologic interventions in C/A populations, clinicians' options beyond these routes are limited. Increasing popularity of online CBT programs, however, offers a positive resolution to accessibility issues. Overall, the $\mathrm{C} / \mathrm{A}$ population remains untended in comparison to adult populations, to which more efficient assessment methods are available, and new treatment approaches are continuously being modified - such as combining CBT and ACT. Nonetheless, there are certain barriers to successful and available treatment across the collective age-spectrum - including cost, time, and accessibility.

With mental disorders such as GAD being among the most significant threats to public health, it is critical that successful prevention and intervention measures are easily accessible. If more is understood in terms of etiological factors and course, then prevention and treatment methods can improve. Therefore, while the availability of new assessment and treatment models are a

Table 4: Summary of GAD treatment options for adults.

\begin{tabular}{|c|c|c|}
\hline & Cognitive Behavioral Therapy (CBT) & $\begin{array}{l}\text { Acceptance and Commitment Therapy } \\
\text { (ACT) }\end{array}$ \\
\hline Method & $\begin{array}{c}\text { Client learns about the nature of his/her } \\
\text { anxiety while building strategies for man- } \\
\text { aging physical symptoms, problem-solving } \\
\text { skills, and worry tolerance, while also iden- } \\
\text { tifying and challenging anxiety-provoking } \\
\text { thoughts /images }\end{array}$ & $\begin{array}{c}\text { Utilizes the process of acceptance, in } \\
\text { which clients' psychological flexibility is } \\
\text { enhanced to counter experiential avoid- } \\
\text { ance and ineffective coping styles, while } \\
\text { maximizing engagement in meaningful } \\
\text { daily activities }\end{array}$ \\
\hline Administration & Face-to-face or online & Face-to-face \\
\hline Effectiveness & $\begin{array}{l}\text { Up to } 66 \% \text { of clients experience improve- } \\
\text { ments in anxiety after } 9.5 \text { sessions of CBT } \\
\text { (Gould et al., 1997) }\end{array}$ & $\begin{array}{l}\text { Approximately } 50 \% \text { of clients report sig- } \\
\text { nificantly improved quality of life (Roemer } \\
\text { and Orsillo, 2007) }\end{array}$ \\
\hline
\end{tabular}


concern, further investigations into the onset of GAD and preventive measures remain essential moving forward.

\section{Acknowledgements}

The authors would like to thank Dr. Andrew Howell for agreeing to oversee this project. In addition to making the completion of this paper possible, Dr. Howell's insightful revisions and suggestions proved to be invaluable in our development as academics.

\section{Abbreviations}

GAD: Generalized Anxiety Disorder

C/A: Children and Adolescent

ADIS-C: Anxiety Disorders Interview Schedule for

Children

YAM-5: Youth Anxiety Measure for DSM-5

GADQ-IV: Generalized Anxiety Disorder

Questionnaire-IV

PSWQ: Penn State Worry Questionnaire

GAD-7: Generalized Anxiety Disorder 7-Item

CBT: Cognitive Behavioral Therapy

ACT: Acceptance and Commitment Therapy 


\section{References}

American Psychiatric Association (2013). Diagnostic and statistical manual of mental disorders (5th edition). Arlington, VA: American Psychiatric Association.

American Psychiatric Association. (1987). Diagnostic and statistical manual of mental disorders. (3rd ed., text rev.). Arlington, VA: American Psychiatric Association. https://doi.org/10.1176/dsm 10.1176/appi.books.9780890420188.dsm-iii- r

Barlow, D.H. (2004). Anxiety and its disorders: The nature and treatment of anxiety and panic (2nd edition). New York: Guilford.

Beck Institute for Cognitive Behaviour Therapy. (2016). CBT FAQs: You have questions, we have answers! Retrieved from https://www.beckinstitute.org/get-informed/cbt-faqs/

Behar, E., DiMarco, I. D., Hekler, E. B., Mohlman, J., \& Staples, A. M. (2009). Current theoretical models of generalized anxiety disorder (GAD): Conceptual review and treatment implications. Journal of Anxiety Disorders, 23, 1011-1023. https://doi.org/10.1016/j.janxdis.2009.07.006

Beidel, D. C., Turner, S. M., Sallee, F. R., Ammerman, R. T., Crosby, L. A., \& Pathak, S. (2007). SET-C versus fluoxetine in the treatment of childhood social phobia. Journal of American Academy of Child Adolescent Psychiatry, 46, 1622-1632. https://doi.org/10.1097/chi.0b013e318154bb57

Brenes, G.A., Danhauer, S.C., Lyles, M.F., Hogan, P.E., \& Miller, M.E. (2015). Telephone-delivered cognitive behavioral therapy and telephone-delivered nondirective supportive therapy for rural older adults with generalized anxiety disorder: A randomized clinical trial. JAMA Psychiatry, 72(10), 10121020. https://doi.org/10.1001/jamapsychiatry.2015.1154

Borkovec, T. D., Alcaine, O. M., \& Behar, E. (2004). Avoidance theory of worry and generalized anxiety disorder. In: R. Heimberg, C. Turk, \& D. Mennin (Eds.), Generalized anxiety disorder: advances in research and practice (pp. 77-108). New York, NY, US: Guilford Press.

Borkovec, T. D., \& Roemer, L. (1995). Perceived functions of worry among generalized anxiety disorder subjects: distraction from more emotionally distressing topics? Journal of Behavior Therapy and Experimental Psychiatry, 26, 25-30. https://doi.org/10.1016/0005-7916(94)00064-S

Borkovec, T. D., \& Inz, J. (1990). The nature of worry in generalized anxiety disorder: A predominance of thought activity. Behaviour Research Therapy, 28, 153-158. Retrieved from https://www.ncbi.nlm. nih.gov/pubmed/2183759

Brown, T. A., Antony, M. M., \& Barlow, D. H. (1992). Psychometric properties of the Penn State Worry Questionnaire in a clinical anxiety disorders sample. Behaviour Research and Therapy, 30, 33-37. https://doi.org/10.1016/0005-7967(92)90093-V

Canadian Mental Health Association. (2016). Fast facts about mental illness. Retrieved from http://www. cmha.ca/media/fast-facts-about-mental-illness/\#.WMRu9xgZOqQ0)

Cassidy, J., Lichtenstein-Phelps, J., Sibrava, N. J., Thomas, C. L., \& Borkovec, T. D. (2009). Generalized anxiety disorder: Connections with self-reported attachment. Behavior Therapy, 40, 23-38. https://doi.org/10.1016/j.beth.2007.12.004

Cheng, K., \& Myers, K. M. (2011). Child and adolescent psychiatry: The essentials. Retrieved from http:// www.worldcat.org/title/child-and-adolescent-psychiatry-the-essentials/oclc/759169145 eMentalHelath.ca. (2017).

Craske, M., Wittchen, U., Bogels, S., Stein, M., Andrews, G., \& Lebeau, R. (2013). Severity Measure for Generalized Anxiety Disorder. American Psychiatric Association.

Dugas, M. J., Gagnon, F., Ladouceur, R., \& Freeston, M. H. (1998). Generalized anxiety disorder: A preliminary test of a conceptual model. Behaviour Research and Therapy, 36, 215-226. https://doi. 
org/10.1016/S0005-7967(97)00070-3

Eisenberg, D., Gollust, S., Golberstein, E., \& Hefner, J. (2007). Prevalence and correlates of depression, anxiety, and suicidality among university students. American Journal of Orthopsychiatry, 77, 534542.

Ginsburg, G. S., Becker, E. M., Keeton, C. P., Sakolsky, D., Piacentini, J., Albnano, A. M., . . \& Kendall., P. C. (2014). Naturalistic follow-up of youths treated for pediatric anxiety disorders. JAMA Psychiatry, 71, 310-318. https://doi.org/10.1001/jamapsychiatry.2013.4186

Gould, R., Otto, M., Pollack, M., \& Yap, L. (1997). Cognitive behavioral and pharmacological treatment of generalized anxiety disorder: A preliminary meta-analysis. Behavior Therapy, 28, 285-305.

Hayes-Skelton, S.A., \& Roemer, L. (2013). A contemporary view of applied relaxation for generalized anxiety disorder. Cognitive Behaviour Therapy, 42(4), 292-302. https://doi.org/10.1080/16506073 .2013 .777106

Huppert, J., \& Sanderson, W. (2010). Psychotherapy for generalized anxiety disorder. In D.J. Stein, E. Hollander, \& B.O. Rothbaum (Eds.), Textbook of Anxiety Disorders (253-274). Arlington, VA, U.S.A.: American Psychiatric Publishing, Inc.

Locke, A. B., Kirst, N., \& Shultz, C. G. (2015). Diagnosis and management of generalized anxiety disorder and panic disorder in adults. American Academy of Family Physicians, 91, 617-624. Retrieved from https://www.shastahealth.org/sites/default/files/residency/Diagnosis-and-Management-ofGeneralized-Anxiety-Disorder-and-Panic-Disorder-in-Adults.pdf

Luoma, J. B., Hayes, C. S., \& Walser, R. D. (2007). Learning ACT: An Acceptance and Commitment Therapy skills-training manual for therapists. Oakland, CA: New Harbinger.

Mennin, D. S., Heimberg, R. G., Turk, C. L., \& Fresco, D. M. (2002). Applying an emotion regulation framework to integrative approaches to generalized anxiety disorder. Clinical Psychology: Science and Practice, 9, 85-90. https://doi.org/10.1093/clipsy.9.1.85

Meyer, T. J., Miller, M.L., Metzger, R.L., \& Borkovec, T.D. (1990). Development and validation of the Penn State Worry Questionnaire. Behaviour Research and Therapy, 28, 487-495. https://doi. org/10.1016/0005-7967(90)90135-6

Milton, J., Polmear, C., \& Fabricius, J. (2011). A short introduction to psychoanalysis (2nd Edition). Los Angeles, USA: SAGE.

Mowrer, O. H. (1947). On the dual nature of learning: A re-interpretation of "conditioning" and "problem solving". Harvard Educational Review, 17, 102-148.

Muris, P., Simon, E., Lijphart, H., Bos, A., Hale, W., \& Schmeitz, K. (2017). The Youth Anxiety Measure for DSM-5 (YAM-5): Development and first psychometric evidence of a new scale for assessing anxiety disorders symptoms of children and adolescents. Child Psychiatry Human Development, 48, 1-17. https://doi.org/10.1007/s10578-016-0648-1

Newman, M., Llera, S., Erickson, T., Przeworksi, A., \& Castonguay (2013). Worry and generalized anxiety disorder: A review and theroretical synthesis of evidence on nature, etiology, mechanisms, and treatment. The Annual Review of Clinical Psychology, 9, 275-297.

Newman, M., Zuellig, A., Kachin, K., Constantino, M., Przeworski, A., Erickson, \& Cashman-McGrath, L. (2002). Preliminary reliability and validity of the generalized anxiety disorder questionnaire-IV: A revised self-report diagnostic measure of generalized anxiety disorder. Behavior Therapy, 33, 215-233.

Piacentini, J., Bennett. S., Compton, S., Kendall, P., Birmaher, B., Albano, A. M., March, J., Sherrill, J., Sakolsky, D., Ginsburg, G., Rynn, M., Bergman, R. L., Gosch, E., Waslick, B., lyengar, S., McCracken, 
J., \& Walkup, J. (2013). 24- and 36-week outcomes for the child/adolescent anxiety multimodal study (CAMS). Journal of American Academy of Child Adolescent Psychiatry, 53, 297-310. https:// doi.org/10.1016/j.jaac.2013.11.010

Rapee, R. (1991). Generalized anxiety disorder: A review of clinical features and theoretical concepts. Clinical Psychology Review, 11, 419-440.

Roemer, L. \& Orsillo, S. (2007). An open trial of an acceptance-based behaviour therapy for generalized anxiety disorder. Behavior Therapy, 38, 72-85.

Roemer, L., \& Orsillo, S. M. (2002). Expanding our conceptualization of and treatment for generalized anxiety disorder: Integrating mindfulness/acceptance-based approaches with existing cognitivebehavioral models. Clinical Psychology: Science and Practice, 9, 54-68. https://doi.org/10.1093/ clipsy.9.1.54

Silverman, W. K., \& Nelles, W. B. (1988). The Anxiety Disorder Interview Schedule for Children. Child \& Adolescent Psychiatry, 27, 772-778. https://doi.org/10.1097/00004583-198811000-00019

Silverman, W., K., Saavedra, L., M., \& Pina, A., A. (2001). Test-retest reliability of anxiety symptoms and diagnoses with anxiety disorders interview schedule for DSM-IV: Child and parent versions. Journal of the American Academy of Child and Adolescent Psychiatry, 40, 937-944. https://doi. org/10.1097/00004583-200108000-00016

Simon, E., Bos, A. E. R., Verboon, P., \& Muris, P. (2017). Psychometric properties of the Youth Anxiety Measure for DSM-5 (YAM-5) in a community sample. Personality and Individual Differences, 116, 258-264. https://doi.org/10.1016/j.paid.2017.04.058.

Spek, V., Cuijpers, P., NykIAcek, I., Riper, H., Keyzer, J. and Pop, V. (2007). Internet-based cognitive behaviour therapy for symptoms of depression and anxiety: a meta-analysis. Psychological Medicine, 37, 319-328. https://doi.org/10.1017/S0033291706008944

Spence, S. H., Donovan, C. L., March, S., Gamble, A., Anderson, R., Prosser, S., Kercher, A., \& Kenardy, J. (2008). Online CBT in the treatment of child and adolescent anxiety disorders: Issues in the development of BRAVE-ONLINE and two case illustrations. Behavioural and Cognitive Psychotherapy, 36, 411-430. https://doi.org/10.1017/S135246580800444X

Spitzer, R. L., Kroenke, K., Williams, J. B., \& Löwe, B. (2006). A brief measure for assessing generalized anxiety disorder. Archives of Internal Medicine, 166, 1092-1097. https://doi.org/10.1001/ archinte.166.10.1092

Statistics Canada. (2015, November 27). Section B-Anxiety Disorders. Retrieved July 31, 2017 from Statistics Canada Web site: http://www.statcan.gc.ca/pub/82-619-m/2012004/sections/ sectionb-eng.htm\#a4

Velting O. N., Setzer, N. J., \& Albano, A. M. (2004). Update and advances in assessment and cognitivebehavioural treatment of anxiety disorders in children and adolescents. Professional Psychology: Research and Practice, 35, 42-54.

Waddell, C., Shepherd, C., Schwartz, C., \& Barican, J. (2014, June). Child and youth mental disorders: Prevalence and evidence-based interventions. Retrieved from http://childhealthpolicy.ca/wpcontent/uploads/2015/12/2015-10-05-Waddell-et-al-Report-2014.06.16-w-errata.pdf

Wagner, K. D. (2001). Generalized anxiety disorder in children and adolescents. Psychiatric Clinics of North America, 24, 139-153. https://doi.org/10.1016/S0193-953X(05)70210-0

Walkup J. T., Albano, A. M., Piacentini, J., Birmaher, B., Comptom, S. N., Sherrill, J. T., Ginsburg, G. S., Rynn, M. A., McCracken, J., Waslick, B., lyengar, S., March, J. S., \& Kendall, P. C. (2013). Cognitive behavioural therapy, sertraline, or a combination in childhood anxiety. New England Journal of 
Medicine, 359, 2753-2756. https://doi.org/10.1056/NEJMx110064

Wehry, A. M., Beesdo-Baum, K., Hennelly, M. M., Sucheta, D. C., \& Strawn, J. R. (2015). Assessment and treatment of anxiety disorders in children and adolescents. Current Psychiatry Reports, $17,589$. https://doi.org/10.1007/s11920-015-0591-z

Wells, A. (1995). Metacognition and worry: A cognitive model of generalized anxiety disorder. Behavioral and Cognitive Psychotherapy, 23, 301-320. https://doi.org/10.1017/S1352465800015897

Wetherell, J., Afari, N., Ayers, C., Stoddard, J., Ruberg, J., Sorrell, J., . . \& Patterson, T. (2011). Acceptance and commitment therapy for generalized anxiety disorder in older adults: A preliminary report. Behavior Therapy, 42, 127-134.

Wittchen, H. \& Hoyer, J. (2001). Generalized anxiety disorder: Nature and course. Journal of Clinical Psychiatry, 62, 15-19. https://doi.org/10.1037/0735-7028.35.1.42 